\title{
Freedom and moral enhancement
}

This issue of Journal of Medical Ethics includes a pair of papers debating the implications of moral bioenhancement for human freedom-and, especially, the question of whether moral enhancement should potentially be compulsory. In earlier writings Ingmar Persson and Julian Savulescu (P\&S) argue that compulsory moral bioenhancement may be necessary to prevent against catastrophic harms that might result from immoral behaviour. ${ }^{1}$ In "Voluntary moral enhancement and the survival-at-any-cost bias" Vojin Rakic agrees with P\&S that moral bioenhancement is important, but he argues that bioenhancement interventions should be voluntary rather than compulsory (see page 246).

Both Rakic and P\&S disagree with Harris, who denies that moral enhancement could involve interventions beyond cognitive enhancement. Moral enhancement would essentially involve cognitive enhancement, according to Harris, because moral behaviour requires ability to distinguish right from wrong-ie, awareness and rational capacity. ${ }^{2}$ While Harris admits that those who know what is right might not always do what is right, he argues that we could not altogether prevent people from doing what is wrong (via moral enhancements) without destroying freedom essential to their moral agency.

According to Rakic, however, the fact that people who know what is right might not always do what is right reveals that mere cognitive enhancement would be inadequate to prevent immoral behaviorbecause much immoral behaviour results from weakness of will. Because people could freely chose to undergo moral enhancement, furthermore, according to Rakic, "our freedom will not be curtailed by it". Presumably Rakic here supposes that if a person freely choses to be in State A (e.g., more altruistic, with less weakness of will, and morally better motives, etc.) then State A is necessarily compatible with-and a reflection of-her human freedom. Forcing a person to be in State A, on the other hand, would obviously involve freedom infringement. While this latter point is surely correct, it is not obvious that a person's free choice to be in some state entails that the state in question is a free one. One might freely decide to smoke, drink, or shoot up-but if he thereby ends up an addict we would not want to say that the state of addiction is fully free (in virtue of the free choice that led to addiction). Similar things might be said about one freely selling herself into slavery. The point here is that one can freely chose to give up his freedom and/or freely choose to do things that will result in its compromise. Freely chosen moral enhancement would thus not necessarily make moral enhancement compatible with freedom.

According to P\&S, questions about moral enhancement only arise if there is a sense in which we lack freedom to begin with-because "if our will is indeterministically free by nature, we cannot make it determined that we will behave morally, which fully effective moral bioenhancement requires" (see page 251). While it may be correct that a fully causally determined world would be required for fully effective moral bioenhancements, a remaining question is whether moral bioenhancements might not be partially effective if the world is not fully causally determined. It seems theoretically possible that moral bioenhancements might make us less likely, though still ultimately free (in an indeterminstic sense), to act immorally-and this might be enough to prevent the catastrophic consequences that $P \& S$ are ultimately worried about.

Without getting too bogged down in a perplexing discussion of the metaphysics of free will, let us focus on the question of whether or not compulsory moral enhancement might be ethically appropriate. Though compulsory intervention by definition involves compromise of some freedom(s), compulsion need not involve a net loss of freedom. Compulsory bioenhancements remove the freedom to choose whether or not to be morally enhanced-but they might sometimes result in a net gain of freedom for those coerced. Those made less likely to commit criminal actions, for example, will be less likely to end up in jail. The freedom enabled by law-abiding life might thus outweigh the freedom costs of mandatory intervention. This, and the discussion about free action leading to addiction and so on, raises difficult questions about how freedom should be measured. We need a good metric of freedom in order to determine what the overall implications of moral enhancement for freedom would be.

A reason to worry about reliance on voluntary moral bioenhancement, in any case, is that those most likely to commit heinous acts with catastrophic consequences are probably not especially likely to volunteer for moral enhancement. Assuming, for the sake of argument, that mandatory moral enhancement would involve a net liberty cost for those who are enhanced (and this is dubious if mandatory enhancement in effect prevents the destruction of human life) this would not necessarily mean that mandatory enhancement would be morally unacceptable. First, a net loss of liberty does not entail a complete loss of liberty. Under a regime of mandatory enhancement, people would maintain wide-ranging freedom of conduct. A net loss of freedom need not entail that "freedom would no longer be intact"-a net loss of freedom might simply mean that some freedom is lost (while overall freedom remains largely intact). As noted by $P \& S$, freedom is a matter of degree.

Second, as also noted by P\&S, freedom is not the only thing that matters morally. We sometimes rightly infringe on people's freedoms in order to promote achievement of other societal goals such as utility (ie, aggregate well-being). The ethical acceptability of mandatory moral enhancement thus largely depends on the magnitude of benefits-e.g., in terms of utility-that mandatory moral enhancement is likely to have. If the utility gains of mandatory moral enhancement are likely to be enormous, then the net liberty loss (if any) might be justified. If the utility gains are likely to be nil or only very minor, on the other hand, then the liberty costs might not be justified.

The ethical acceptability of moral enhancement thus turns on key, unresolved empirical and philosophical questions. The empirical questions concern the magnitude of liberty loss from mandatory enhancement and the magnitude of utility gain that might be expected from mandatory moral enhancement. As noted by $P \& S$, the extent of utility gain that might be expected from mandatory enhancement partly depends on how safe and effective moral enhancements turn 
out to be. As noted by Rakic, the extent of the expected utility gain also depends on the extent to which moral enhancement reduces likelihood of catastrophe. Philosophical questions (that have a bearing on some of the empirical questions) concern how liberty and utility (and any other values at stake) should be measured. Assuming we had good metrics for liberty and utility, and that we could accurately predict what the liberty costs and utility gains would be in the case of mandatory moral enhancement, the million dollar philosophical question concerns how we should strike a balance or make trade-offs between these two kinds of goods in cases of conflict-ie, how great would expected utility gains need to be in order for liberty costs of a given magnitude to be justified? ${ }^{3}$

It is worth noting that the question "Should enhancements be mandatory or voluntary?" (as though there were an either-or distinction to be made) might ultimately be a red herring. Rather than appealing to a binary distinction between mandatory and voluntary interventions, we should recognize that possible interventions range from those that are most strongly encouraged (at one end of the spectrum) to those that are most strongly discouraged (at the other end of the spectrum). Degrees of encouragement are a function of the strength of the incentive provided-ie, we could provide greater or smaller financial incentives for people to be morally enhanced. Degrees of discouragement are a function of the strength of the disincentive provided-ie, we could pose weaker (small fine) or stronger threats (larger fine or, stonger still, imprisonment) to discourage enhancement refusal. Thinking in terms of degrees of encouragement and discouragement facilitates thinking about freedom in terms of degree-ie, one is free to do something to the degree that she is not (strongly) discouraged from doing so, or to the degree that she is not provided with strong incentives to do otherwise. (Rakic suggests the possibility of incentivising moral enhancement, but he fails to acknowledge that this might detract from freedom to refrain from taking incentivised action-just as the threat of being told you will be shot if you don't do something detracts from the freedom not to do it. The greater the costs of not doing something, the less free we are to do otherwise. Forgone rewards count as costs.) We might conclude that the strength of encouragement to be morally enhanced-or the strength of discouragement to remain unenhancedshould be proportional to the utility gains expected to result from moral enhancement. Moral enhancement should thus be mandatory-or voluntary-to an appropriate degree. Welcome to scalar bioethics ...

\section{REFERENCES}

1 Persson I, Savulescu J. The Perils of cognitive enhancement and the urgent imperative to ehhance the moral character of humanity. J Appl Philos 2008;25:162-77.

2 Harris J. Moral enhancement and freedom. Bioethics 2011;25:102-11.

3 Selgelid MJ. A moderate pluralist approach to public health policy and ethics. Public Health Ethics 2009;2:195-205. 